Y. Ikeda, C. M. Herr, D. Holzer, S. Kaijima, M. J. Kim. M, A, Schnabel (eds.), Emerging Experience in Past, Present and Future of Digital Architecture, Proceedings of the 20th International Conference of the Association for Computer-Aided Architectural Design Research in Asia CAADRIA 2015, 489-497. (C) 2015, The Association for Computer-Aided Architectural Design Research in Asia (CAADRIA), Hong Kong

\title{
FLOWING THROUGH SPACE
}

\section{Leveraging game mechanics to enhance the studio experience}

\author{
TANE J. MOLETA ${ }^{1}$, \\ 1, Victoria University of Wellington, Wellington, New Zealand \\ tane.moleta@vuw.ac.nz
}

\begin{abstract}
The general field this presentation will address is the integration of game mechanics within the design studio. The CAAD community has invested considerable energy into the insertion of games within education to teach specific skills or develop design behaviours. Building on some of this research we report on three years of studio teaching in undergraduate architectural studies. We propose that the outcomes of the design studio can benefit greatly from employing game mechanics to encourage constructive design behaviours within a student cohort. This body research flips the traditional location of game mechanic, shifting the motivations from the hands of the teacher to place the mechanic in the hand of the student. The research reports an increased level of engagement and collaboration and presents a body of work that extends beyond traditional expectations of the architectural design studio.
\end{abstract}

Keywords. Education, game mechanics, design studio.

\section{Challenges to the contemporary design studio}

Change is the constant in architectural education. Demonstrating a perpetual requirement to adapt and evolve (Westfall, 2008), the discipline is continually challenged from an increasingly wide range of pressures. Architectural education has received influence from the Old world (Barnstone, 2008; Maulsby, 2009), the New world (Caruso, 2008; Littmann, 2000) and from Australasia (Askland and Australia, 2012; Luscombe, 1995; Roudavski, 2011). Higher education has had to weather development in, construction methods (Altheide, 1989; Berry and Moss, 2008; Carey, 1992), aesthetic and philosophical sensibilities (Brady, 1996; Gül, 2011; Weismehl, 1967) and to 
technology and modes of design (Abdelfattah, 2004; Abdelhameed, 2012; Achten, 2009; Bates and Sangra, 2011). According to Ostwald \& Williams's survey of architectural education in Australasia, the most impacting of these developments stem from changes to funding structures offered to universities by central governments (Askland and Australia, 2012). They state, a general increase in student numbers, including international intakes (.ibid), a shift from industry tutelage or full time academic teaching staff to undergraduate teacher support, and larger class sizes are used to alleviate rising fiscal burdens suffered by contemporary schools of architecture. (Askland and Australia, 2012, p. 13). The compound of these conditions can be concluded to have a negative effect on the capacity of schools of architecture to deliver a consistent level of education. What this amounts to is that students in schools of architecture will see increasingly less exposure to experienced educators which will have a profound effect on the role of the design studio.

The proposition this research makes is that by embedding game mechanics within studio projects, students exhibit positive educational outcomes. This research acknowledges that for some time game engines have offered architectural students a compelling environment to inhabit architectural designs. One missed opportunity however, is that frequently game engines can be seen as a visualisation tool for use at the end of the design process, rather than a design ideation tool, or even less so a method to embed constructive design studio behaviours. This presentation demonstrates this observation through a number of student projects that use game engines in the architectural design studio.

\section{Game mechanics to provide an engaging learning experience}

The concept of game mechanics as a model for evoking an engaging learning experience for participants is not new. Countless researchers have noted that one of the most compelling aspects observed of electronic games is their capacity to actively engage a participant (Sharma and Whitton, 2011; Whitton, 2009). This capacity to engage has been largely attributed to the use of game mechanics (Nitsche, 2008). Michael Nitsche describes in his book 'Video Game Spaces' that game mechanics are 'a set of circumstances' and that they are, 'used in games to encourage players to participate in the activity's required of the game'(Nitsche, 2008). Jesse Schell defines these circumstances primarily as a 'set of challenges' that the participant 'must adhere too', or 'master' as a means to progress within that game (Schell, 2008, p. 177). In extension to this position, Schell articulates two key points. Firstly, that the participant must be led to believe that they can indeed master the skills required to proceed through the game (Schell, 2008, p. 176). The se- 
cond consideration is the notion of interplay between anxieties versus boredom (Schell, 2008, p. 119). This stipulates that the participant engaged in any stage of game activity must operate within a balance between challenges (difficulty - low to high), and required skill acquisition to surpass those challenges (ease of acquiring skill - low to high). Challenges would seem to be a particularly key aspect to the game mechanic. Schell describes the approach to solving these challenges as a series of opportunities to effect meaningful choice within the game environment (Schell, 2008, p. 179). In many game environments, the opportunity to effect choice is exhaustive, yet an abbreviated selection of examples might take these forms:

- How should I spend my resources

- What should I practice to try to perfect

- Should I try to get through quickly or carefully

- What strategy should I use in this situation

- Would I play it safe, or should I take a big risk

Questions such as, 'how should I spend my resources', 'what should I practice to try and perfect', and 'what strategy should I use in this situation' are all highly relevant questions that designers should apply to their studies. Yet the reality is that in many cases, students often approach projects with either a functional - 'just get it done' attitude, or a blind forward march without paying much heed to the advice of peers or of teaching staff.

\section{The studio}

The aims of an educator are balanced between the outcomes of a set piece of project work, and subsequently how the working might contribute to the development of constructive design habits. The subject delivered to students in this class provides a theoretical overview and practical introduction to the use of mixed reality for designers. The emphasis is on the real time evaluation of phenomenon - visual, aural, and tactile using digital models within design contexts. The theoretical backdrop is the tradition of phenomenology in architectural and landscape design. While this has a philosophical pedigree related to the nature of reality and how we make sense of the world, for designers the focus is more pragmatic. While a design might be inspired by any number of abstract ideas - analogy, metaphor, geometric patterns etc. It will be realised in physical form and be experienced as phenomena. That is, by the body in motion, using primarily our visual, aural and tactile senses. Robin Evans in his seminal work on the relation between drawing and building, discusses the art of being able to imagine, through the abstraction of 
drawing, the physical experience of built form (Evans, 2000). One of the possibilities offered by digital technology is to close the gap in the translation from drawings, to explore the 'presence' of designs before they are constructed. While accepting that any simulation or scale model will not give the full sense of 'being there', the use of digital phenomena enables some of the experiential qualities of a design to be explored prior to construction.

The brief delivered to the students in this class was divided into two parts. The first half was to produce a navigable 3D virtual environment of the Wellington city waterfront, New Zealand. The environment was to be lightmapped, contain weather, sound and haptic events. The second part of the project required students to reinterpret their section of the city through the insertion of an architectural intervention that would better facilitate navigation of the city as a Parkour athlete. The theoretical context for evolving the designs was defined by Lynches five elements of urban way finding. Student were given the following method of analyzing urban legibility based on the five elements of; paths, edges, districts, nodes and landmarks defined by Lynch as follows:

- Paths: are described as familiar routes followed: "Are the channels along which the observer customarily, occasionally, or potentially moves." E.g.streets, walkways, transit lines, canals, railroads."

- Edges: Are described as the dividing lines between districts: "are the linear elements not used or considered as paths by the observer. They are boundaries between two phases, linear breaks in continuity." E.g.- shores, railroad cuts, edges of development, walls."

- Districts: Are described as areas with perceived internal homogeneity: Lynch notes that they "are medium-to-large sections of the city, conceived of as having two-dimensional extent, which the observer mentally enters 'inside of,' and which are recognizable as having some common identifying character"

- Nodes: Are described as center of attraction that you can enter- "Are points, the strategic spots in a city into which an observer can enter. The nodes may be simply concentrations, which gain their importance from being the condensation of some use or physical character, as a street-corner hangout or an enclosed square."

- Landmarks: Are described as point of reference- "Are another type of pointreference, but in this case the observer does not enter within them, they are external. They are usually a rather simply defined physical object which makes one orient oneself." 
The students enrolled in this paper were $3^{\text {rd }}$ year and $4^{\text {th }}$ year students coming from backgrounds in Architecture, Interior Architecture and Landscape Architecture. The paper is offered twice a year and has enrolments of 40-60 students each term. The tools chosen were the Autodesk Suite, which was used primarily for 3D model generation, texturing, animation and the Unity3D game engine, which was used to embed the 3D content and offer the ability to interactively navigate the architecture within a digital environment. As an elective paper the students met twice a week for 4 hours in total and the project duration was 12 weeks. Learning was supported by weekly lectures, design studios and teaching support at a 1:18 ratio of teacher to student.

\section{Project descriptions}

In Student Project One, the student chose to augment possible views of the urban environment by placing a number of animated levitated platforms above the main civic area. The main game mechanic they chose to employ was a timed challenge.

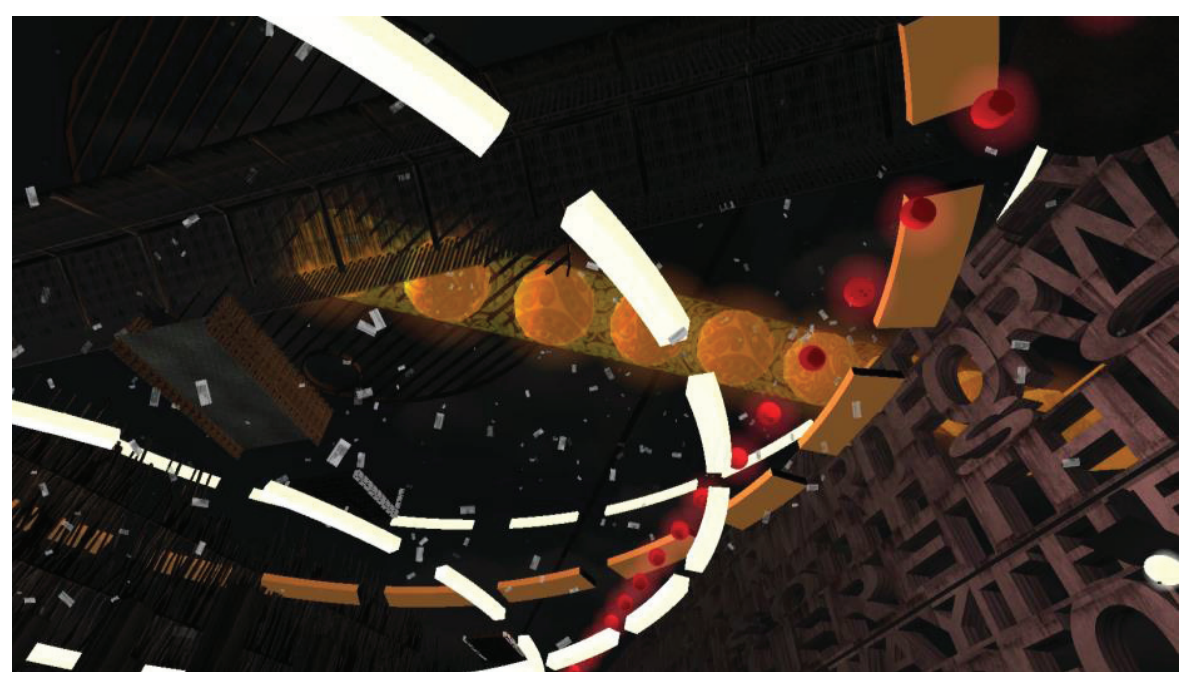

Figure 1. Student Project One

A simple maze like environment was produced by the student and after numerous iterations presented a challenging puzzle to the players of the game. The unintended learning outcome of this project was (aside from a huge skill uptake in scripting) was a highly detailed understanding of the experience of time in urban contexts. In using a $1^{\text {st }}$ person controller, the student became more aware of the human scale within the scheme, and how the 
experience of moving through the space would be interpreted in a way that differed from traditional 3D modelling or plan drawing. Additionally, the fine level control needed for navigation required the student to actively pursue colleagues' opinions, with a focus on improving the scheme without experiencing fatigue or boredom.

The second project presented produced a scheme with a close reading of the natural events that occur in the city. The project requested participants to navigate their way to the foreshore using general knowledge of the city, crossed with a number of audio and visual cues. Conversely, the introduced architectural intervention was designed to confuse navigation in game space, sending participants in counter intuitive directions, and hiding elements of the journey within the detail of the urban environment. Again, the student exhibited a highly enthusiastic approach to the project.

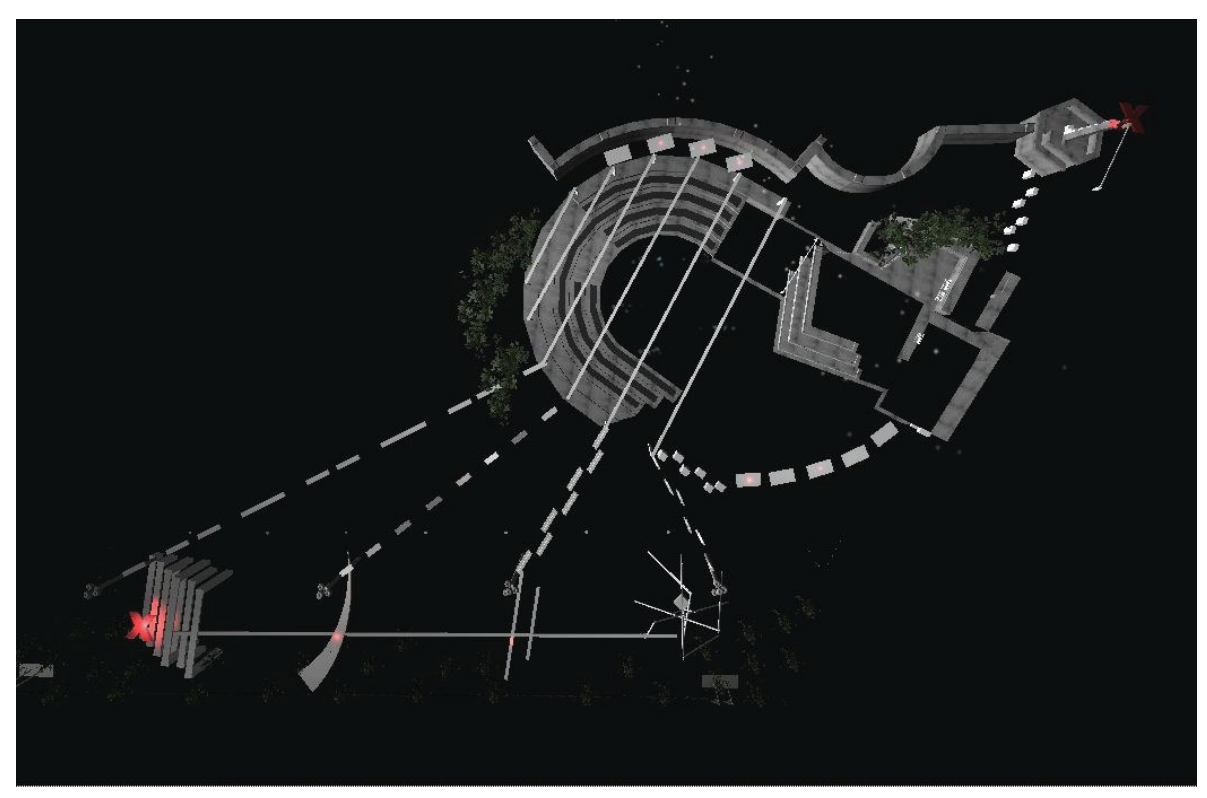

Figure 2. Student Project Two

They showed a real desire to share the scheme with others, receive feedback and improve their work in a way that the same student would not have in a standard studio context. In the effect of delivering a scheme for 'others' - the participant of the game, produced a behaviour that somewhat depersonalised the design process and encouraged a far more informed design process to yielded a vastly more refined outcome. 
The final scheme presents a reconfigured interpretation of inhabiting the city in a unique way. In this particular project the $1^{\text {st }}$ person controller was re-scripted to provide real-time $3^{\text {rd }}$ person views of the participant. While this was the makings for extraordinarily difficult navigation, the outcome went considerable way to present the participants of the game within an alternate view of the urban context within architectural visualisation. Navigation occurred through a series of cinematic like experience of sweeping camera pans throughout a section of the city. Due to the difficulty in playing this project a high number of evaluation sessions were conducted by the student. This resulted in a highly complex but thoroughly enjoyable experience for both creator and players alike.
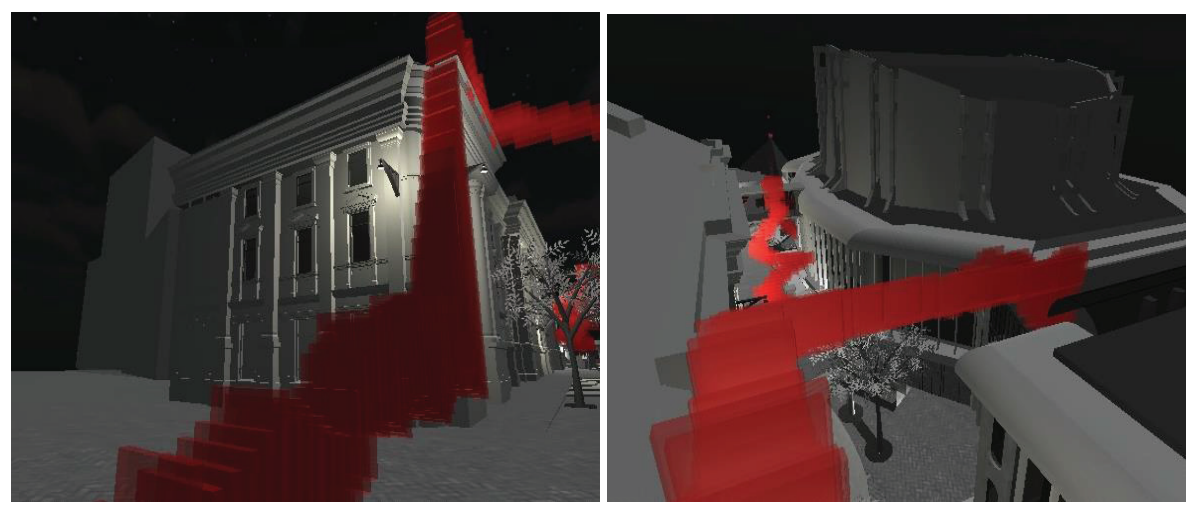

Figure 3. Student Project Three

\section{Discussion}

In the last decade a growing body of research has initiated the use of game mechanics within education. Many of these attempts have focused on delivering tools to aid learning a specific body of knowledge as an addition to taught curricula. In contrast, this study notes that through asking students to develop designs within a game mechanic framework a range of positive pedagogical outcomes can be achieved. Throughout the course of this study the students became more invested within the studio environment, displayed an increased willingness to seek help, and an acknowledgment that the designs are for public consumption. Reflections on individual projects found that this range of factors would reoccur each time the paper was delivered.

In general all schemes used time as a motivator to encourage a purposeful inhabitation of the environment. This has two significant benefits. With the increase of digital literacy one of the most challenging concepts to understand is that of human scale within an architectural context. By asking the 
students to embed a $3^{\text {rd }}$ person controller in their schemes, the students evolve a more thorough understanding of dimension and distance when presented in digital representations. Additionally, all schemes underwent a higher number of design iterations to refine the experience for the participants. Most student methodologies required a number of test stages. Once work was nearing completion, students self-volunteered their projects for testing and sought advice on how to improve the experience. Complexity, and oversized schemed were quickly adjusted. This resulted in an increased sophistication in the design of space and form to influence inhabitation of the environment in a purposeful way. Perhaps more interestingly all candidates demonstrated a willingness to share and collaborate constructively upon one another's schemes. Increasingly, students seem to take a more depersonalised and professional view of their own work. By situating the design interventions in a 'game situation' the students are aware that the work needs to be appreciated by others as a 'real world' experience. This is in considerable contrast to the design studio where students may be very secretive or even protective of their work. This has in some scenarios led to students disregarding advice on design issues from peers due to a 'studio blindness' that the students themselves cannot see the flaws in their work due to the personal commitment to their schemes. In borrowing from the understanding that the game is to be experienced and ultimately enjoyed by others, this paper concludes that by gifting the control of the game mechanic to the student a range of benefits and educational outcomes can be achieved.

\section{Future work}

To extend this study we identify that a number of surveys have been undertaken to establish a range of key learning objectives for graduate architects (Clarke and Johnson, 1987)(Broadbent, 1995)(Beinhart et al., 1981). Within these spatial-arrangement is a key capacity listed. Despite this, a review of contemporary literature concludes that tutelage in spatial-arrangement is not likely to be delivered in foundation year studies, or if at all in later studies. This situation confounds common sense as the skill that is most inclined to take the greatest amount of time to hone should logically be delivered at an early stage to allow the student to grow into this crucial skill set.

The findings from this study indicate that the capacity for students to selfdevelop (as opposed to recipients of tool development) educational understanding can be improved through use of game mechanics. Future work in the area of spatial-arrangement holds significant promise. 


\section{References}

Abdelfattah, H.K. and A.A.R., 2004. No More Fear or Doubt: Electronic Architecture in Architectural Education.

Abdelhameed, W.A., 2012. Micro-Simulation Function to Display Textual Data in Virtual Reality. Int. J. Archit. Comput. 10, 205-218.

Achten, H.H., 2009. Experimental Design Methods -- A Review. Int. J. Archit. Comput. 7, $505-534$.

Altheide, D.L., 1989. The Elusive Mass Media. Int. J. Polit. Cult. Soc. 2, 414-419.

Askland, H.H., Australia, 2012. Assessing creativity: supporting learning in architecture and design. Office for Learning and Teaching (OLT), Sydney.

Barnstone, D.A., 2008. Not the Bauhaus. J. Archit. Educ. 62, 46-55. doi:10.1111/j.1531314X.2008.00215.x

Bates, A.W. (Tony), Sangra, A., 2011. Managing Technology in Higher Education : Strategies for Transforming Teaching and Learning, 1st ed. Jossey-Bass, Hoboken.

Beinhart, J., Schon, D.A., Moore, C., Argryis, C., Bolman, L., Balfour, A., 1981. Architecture Education Study: The papers. Andrew W. Mellon Foundation.

Berry, D., Moss, G. (Eds.), 2008. Libre Culture. Meditations on Free Culture, 2nd ed. Pygmalion Books, Winnipeg.

Brady, D.A., 1996. The Education of an Architect: Continuity and Change. J. Archit. Educ. 1984- 50, 32-49.

Broadbent, M., 1995. Architectural Education, in: Educating Architects. Academy Editions, London.

Carey, J.W., 1992. Technology and Ideology: The Case of the Telegraph, in: Communication as Culture, Revised Edition: Essays on Media and Society. Routledge, pp. 201-227.

Caruso, A.., 2008. Studio Culture: learning from the American experience, in: The Oxford Conference : A Re-Evaluation of Education in Architecture. WIT Press.

Clarke, S., Johnson, P., 1987. Architectural education in the Commonwealth: a second survey of schools. Dept. of Architecture, University of Sydney for the Commonwealth Association of Architects, Sydney.

Evans, R., 2000. The Projective Cast: Architecture and Its Three Geometries. The MIT Press, Cambridge, Mass.

Gül, L.F., 2011. What we learnt from design teaching in collaborative virtual environments Presented at the eCAADe.

Littmann, W., 2000. Assault on the Ecole: Student Campaigns Against the Beaux Arts, 19251950. J. Archit. Educ. 53, 159-166. doi:10.1162/104648800564554

Luscombe, D.O., 1995. Aspects of quality in Australian architectural education. Royal Institute of Architects, New South Wales Chapter, Sydney, N.S.W.

Maulsby, L.M., 2009. Bauhaus Modern and Bauhaus Culture: From Weimar to the Cold War. J. Archit. Educ. 63, 145-147. doi:10.1111/j.1531-314X.2009.01040.x

Nitsche, M., 2008. Video game spaces: image, play, and structure in 3D game worlds. MIT Press, Cambridge, Mass.

Roudavski, S., 2011. Selective Jamming: Digital Architectural Design in Foundation Courses. Int. J. Archit. Comput. 9, 437-462.

Schell, J., 2008. The Art of Game Design : A book of lenses. Morgan Kaufmann, Burlington.

Sharma, R.C., Whitton, N., 2011. Learning with digital games. Br. J. Educ. Technol. 42, E88E88. doi:10.1111/j.1467-8535.2011.01201_10.x

Weismehl, L.A., 1967. Changes in French Architectural Education. J. Archit. Educ. 1947$197421,1-3$.

Westfall, C.W., 2008. Why the Orders Belong in Studio. J. Archit. Educ. 61, 95-107. doi:10.1111/j.1531-314X.2008.00193.x

Whitton, N., 2009. Learning with Digital Games : A Practical Guide to Engaging Students in Higher Education, 1st ed. Routledge, Hoboken. 